\title{
Traumatic Paraplegia in Algeria: Orientation of Early Management ${ }^{\star}$
}

\author{
D. Amara, ${ }^{1}$ M. D., Z. Yagoubi, ${ }^{2}$ M.D., M. Benbakhma, ${ }^{3}$ and
}

A. Ould Quali, ${ }^{3}$ M.D.

${ }^{1}$ Maitre-Assistant, ${ }^{2}$ Proffesseur, ${ }^{3}$ Medecin-Resident. Centre HospitaloUniversitaire de Rèèducation, Fonctionnelle de Tixeraine, Draria, Algeria

In 1978, Algeria, with 20 million inhabitants had only one re-education and rehabilitation centre offering 110 beds, out of which 30 beds were reserved for male paraplegic patients.

Thus from the beginning many negative factors have an influence on the quality of the treatment of patients:

1. Importance of demand.

2. Limited hospitalisation facilities.

3. Very late hospitalisation because of the paraplegics remote residence and their late arrival.

All this has contributed to maintain a true vicious circle:

Too late referral $\rightarrow$ the development of complications

and the increase of time of hospitalisation

The serious situation has caused the authors to try to break the vicious circle by adopting a new attitude, giving priority to early management of posttraumatic paraplegia patients in view of the better prevention of cutaneous, orthopaedic and urinary complications.

Having reported their method of treatment, the authors present a restricted study involving 41 patients taken in 'early', before the 60th day following their injury, briefly giving the most important facts, and stating their conclusions.

^Abstract of paper read at the Meeting of the International Medical Society of Paraplegia and AFIGAP, Hyres, France, January, 1984. 


\section{Study of 41 patients}

(a) Delay before hospitalisation

\begin{tabular}{|c|c|c|c|c|c|c|c|}
\hline Days & $0-10$ & $11-20$ & 21 & & $31-40$ & $41-50$ & $51-60$ \\
\hline $\begin{array}{l}\text { Number of } \\
\text { patients }\end{array}$ & 6 & 13 & & & 7 & 5 & 2 \\
\hline $\begin{array}{l}\text { City of origin } \\
\text { of patients }\end{array}$ & & Algiers & Miliana & Batna & Biskra & Skikda & Annaba \\
\hline $\begin{array}{l}\text { Distance the } \\
\text { patient lives } \\
\text { from the centre }(\mathrm{km}) \\
\text { Delay in } \\
\text { patient ref erral } \\
\text { (days) }\end{array}$ & & 39 & 120 & 450 & 250 & 450 & 600 \\
\hline
\end{tabular}

(b) Type of Treatment

Osteosynthesis: 19; Harrington rods: 11; Roy Camille plates: 8).

Laminectomy: 3.

Non-operative spinal treatment: 19 .

(c) Complications (non-neurological)

Patients referred with bedsores: 12 (small 5; large: 7).

In their study the authors also report the complications caused from using an indwelling catheter (one urethral fistula at the time of referral; six epididymo-orchitis of which four had an abscess; two hydroceles; five bladder calculi, and seven patients had heterotopic ossification).

\section{Conclusions}

The authors note with satisfaction the progressive discontinuance of laminectomy (called 'decompressive') in favour of osteosynthesis. They wish to be involved early with paraplegic patients regarding the care of acute spinal injured patients. They underline the important role of laboratory studies in the treatment of urinary infection, insisting on the prevention of complications from the use of indwelling catheters by better education of the paramedical staff.

Finally, the authors report with satisfaction the recent opening of two new rehabilitation centres which will permit better management of paraplegic patients in Algeria. 